\title{
Development of Small-scale Two-stage Photovoltaic-photothermal Humidification-dehumidification Desalination System
}

\author{
Junquan Zhang ${ }^{1}$, Ke Yang ${ }^{1}$, Changsheng Peng ${ }^{1,2, *}$ \\ 1. The Key Lab of Marine Environmental Science and Ecology of Ministry of Education, \\ Ocean University of China, Qingdao 266100, China \\ 2. School of Environment and Chemical Engineering, Zhaoqing University, Zhaoqing, \\ 526061, China \\ E-mail:pcs005@ouc.edu.cn
}

\begin{abstract}
Air bubble has been proved that it can increase evaporation area and coefficient of mass transfer and heat transfer. Two-stage evaporation system can indirectly increase the contact area of water and vapor, reduce the volume of single evaporation system, and can also combine the multiple systems flexibly. So a new type of small scale two-stage photovoltaic-photothermal humidification-dehumidification (HDH) desalination system is designed, and the relationship between solar radiation and temperature is measured, and the water production capability of the system is investigated. The effect of water temperature, ambient temperature, air flow rate and air temperature on desalination performance is also investigated. The results showed that the rate of water production is positively correlated with sea water temperature, ambient temperature, gas flow rate and air temperature. And the gas temperature is positively correlated with the solar radiation intensity. When the ambient temperature is higher than $25{ }^{\circ} \mathrm{C}$, the cumulative amount of irradiation is $22.3 \mathrm{MJ} / \mathrm{m}^{2}$, the cumulative water production is $19.2 \mathrm{~L} / \mathrm{d}$, and $6.4 \mathrm{~L} /\left(\mathrm{m}^{2} \cdot \mathrm{d}\right)$, the thermal efficiency is 0.66 . The cost of water produced through the designed HDH system is $0.08 \$ / \mathrm{L}$.
\end{abstract}

Key words: Solar energy; Air bubble; Photovoltaic- photothermal; Humidification-dehumidification;

\section{Introduction}

Water is the source of life and the necessities of life activities. It is assumed that by 2025 , more than $60 \%$ of the world's population will face water shortages [1]. Therefore, desalination technologies become more and more important. Desalination technologies have been used to provide fresh water to crews for almost a century [2]. Among the different common desalination processes like multi-stage flash (MSF), multiple-effect distillation (MED), vapor compres-sion (VC), and reverse osmosis (RO) processes are commonly practiced to supply drinking water [1,3-6]. But these technologies demand high energy consumption, high costs of desalination as well as inconvenient to carry. In the side of saving space, smaller solar desalination equipments show greater advantages in ocean-going ships or on distant islands, and the places where electricity and fossil fuels cannot be supplied. Therefore, the application of solar energy to desalination saline water can be a cost effective alternate to fulfill the fresh water demand of ocean going ships and islands. The most direct purpose of solar desalination is to use solar energy to heat the sea water, or use solar energy to power the device to get fresh water. HDH solar desalination systems can work normally at atmospheric pressure. Therefore, the energy consumption equipment of the system is mainly circulating pumps, and they does not require high-tech, so their design, construction and operation are easy. Because of the modular nature of the system, the number of devices can be increased to increase freshwater production [7].

At present, many surveys about the HDH have been done in the world and the characteristics and performance of HDH systems were investigated. Yildirim et al. [7] experimentally investigated the effects of water temperature and gas temperature on the system, and concluded that the impact of water temperature is greater than the gas temperature on the system. Behnam [1] designed a novel HDH system that uses ETC-HP as a highly efficient thermal absorption and conductor device and adds oil between the ETC and HP to increase the freshwater production. Its freshwater productivity is $6.275 \mathrm{~kg} /\left(\mathrm{m}^{2} \cdot \mathrm{d}\right)$. Zhang et al. [8] also studied the humidification process of bubbles by the experiments. The experimental results show that for every $10{ }^{\circ} \mathrm{C}$ increase in the temperature of the bubble humidification, the bubble will simultaneously increase the humidification capacity by $80 \%$. Khalil [9] conducted an experimental study on a solar desalination system with an air bubble column humidifier. In the system, the effect of water temperature, air flow and pore size of the gas distribution plate on the water production of the system was studied. The experimental results show that the 
gained output are $21 \mathrm{~L}$ and the daily efficiency reached at $63 \%$. It came to the conclusion that air bubble column humidifier systems perform better than conventional humidifier systems. It is desirable that the system operates at a lower temperature and that the utilization of solar energy in the system will consume less energy. Zamen et al. [10] designed a two-stage solar HDH system and conducted experimental research on the system. The system uses flat collectors to heat the water. To investigate the effects of ambient temperature on system productivity, Zamen et al. tested the system on hot and cold days of the year, respectively, and found that daily freshwater productivity in the cold season was reduced by half compared to summer daily freshwater productivity. Abd-urRehman [11] experimentally investigated a novel multi stage bubble column humidifier. The system is designed to determine its optimum operating parameters. Farshchi et al. [12] investigated a coupling of a cascade solar still with a HDH system. The effects of feed water and air velocity on the water production of the system were studied. Zhani [13] experimentally studied the impact of water temperature and air on the water yield of the HDH system and conducted an economic analysis. El-Agouz and Abugderah [14] conducted an experimental study on a single-stage bubbling column. The effects of inlet temperature, inlet temperature with velocity on the efficiency of the humidifier were studied. The results show that with the increase of inlet velocity and inlet temperature humidifier greatly enhances the performance. El-Agouz [15] designed a single-stage desalination system with an air HDH method. The influence factors of operation conditions, such as water temperature, brackish water level and air flow on the desalination performance were studied experimentally. Experimental results showed that the system productivity is affected by water temperature, air flow and water level. Wang et al. [16] designed and experimentally researched a photovoltaic (PV) panel-driven HDH and carried out economic and technical analysis. They concluded that the system's processing technology is economically viable and can be easily used for family producing freshwater with solar energy and the remote areas.

As a method to enhance the heat transfer and mass transfer efficiency of seawater, multi-stage flash and multieffect distillation method in the desalination need a lot of spray and vacuum equipment, and require a lot of energy consumption [17]. However, the small scale photovoltaic-photothermal HDH solar desalination as a lowenergy consuming and enhancing heat transfer and mass transfer technology shows a good prospect. Based on this idea, a small scale two-stage photovoltaic-photothermal HDH solar desalination system is designed.

At present, the major problems in seawater desalination systems are: (1) lower heat transfer efficiency, (2) larger power consumption [17], (3) water production instability under low temperature. For the above mentioned problems, a small scale two-stage photovoltaic-photothermal HDH solar desalination system has been designed in this work. The designed systems' has the following characteristics: (1) i. Using the photothermal, ii. two-stage aeration, iii. increase the contact area of gas and water, thereby increase the heat transfer area, so the heat transfer efficiency is higher, (2) i. Using vacuum tube collector on the water heating, ii. air collector preheated into the air can avoid the consumption of conventional energy, iii. reduce the system energy consumption, (3) i. The system covers an area of less than 10 square meters ii. flexible to carry, iii. easy to maintain and low demand of energy, iv. according to local conditions to install. Especially in the ocean-going ships and the island can better reflect its value. Water production is more stable.

\section{Experimental design and work}

Studies have shown that phase change heat transfer and convective heat transfer process have a greater heat transfer coefficient. This paper designs a new type of two-stage photovoltaic-thermal humidificationdehumidification solar desalination system as shown in Fig. 1. The system consists of evacuated tube collectors (ETC), solar air collector (SAC), humidifier (HUM), dehumidifier (DEH), fresh water tanks (FWT) and photovoltaic panel (PVP).

The flow-chart of the system is shown in Fig 2. The seawater of the system absorbs the solar energy and being heated in the ETCs.Then the hot water enters the HUMs from top to bottom. Initially, cold air passes through the SACs and heated, then enters into the bottom of the HUMs under the action of the blower, and then hot air and sea water exchange the heat. A large number of water molecules exchange into the water vapor, and entered into the DEHs to form fresh water under pressure and air flow. Then fresh water, under the case of gravity and air flow, goes into the FWTs. The dehumidified cold air goes back to the SACs, and after being reheated it goes into the HUMs. Sea water that is not evaporated in the HUMs, passes through the three-way valve, part of the sea water, as a supplement to the ETCs, improve the initial temperature of the supply of sea water, is conducive to the heating of the sea water, and the excess sea water is expelled through thick seawater outlet. The power, required for the pumps, fans and other electrical equipments is provided by the photovoltaic panels.

In this paper, the HUM is a two-layer vacuum unit. The uniform aeration panel is designed. A microplate with a diameter of $1 \mathrm{~mm}$ and a $5 \mathrm{~mm}$ hole spacing is placed on the bottom of the evaporator. The hot air is uniformly ejected through the microplate to form a large number of bubbles and the air is humidified. 
(a)

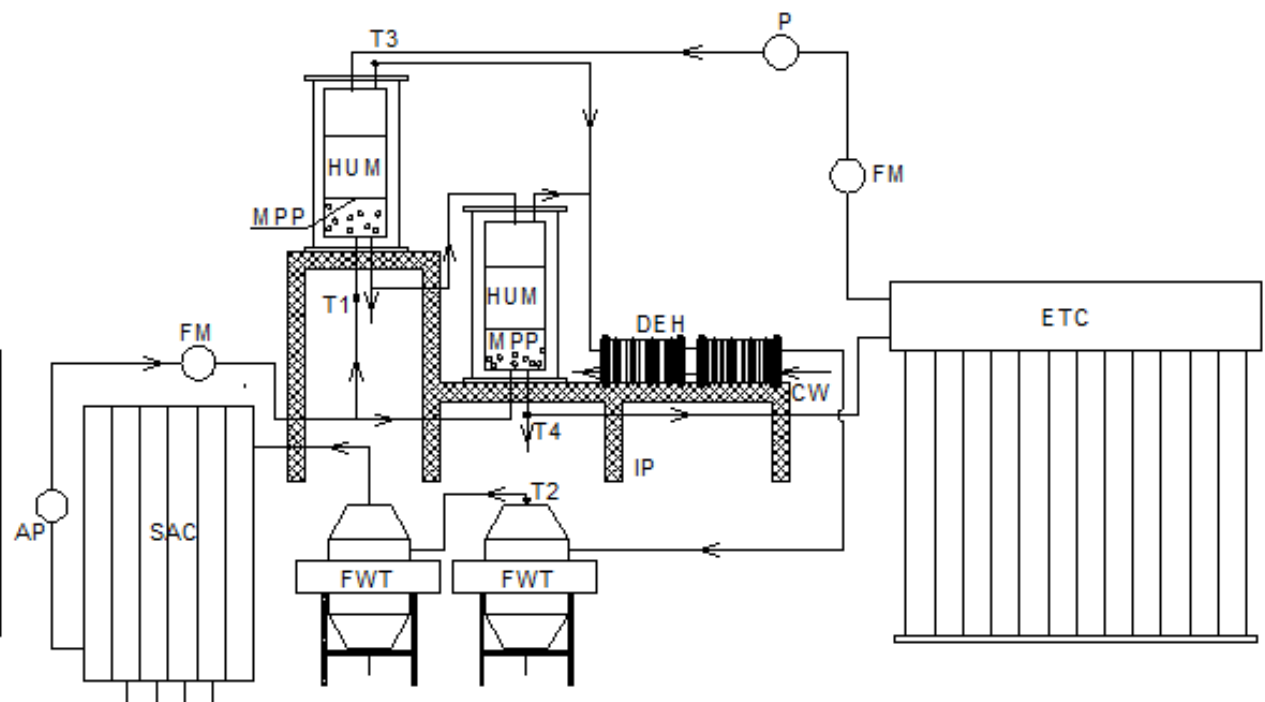

HUM- Humidifier; DEH-Dehumidifier; FWT- Fresh Water Tanks; PVP- Photovoltaic Platel; SAC- Solar Air Collectors ; ETC- Evacuated Tube Collectors; MPP-Micropore Plate; CW-Cooling Water; WP-Water Pump; FM-Flow Meter; IPIron Platform; AP-Air Pump; T1-Inlet Gas Temperature; T2- Outlet Gas Temperature; T3- Inlet Water Temperature; T4Inlet Water Temperature

Fig.1. The schematic diagram of designed system

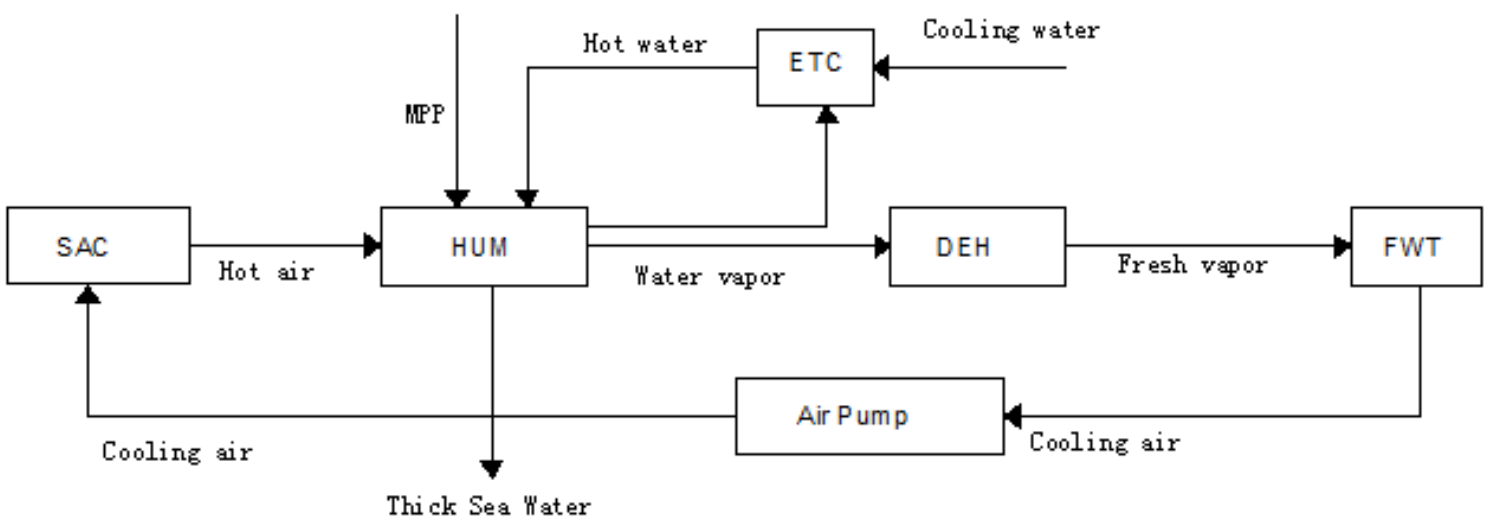

Fig.2. The flow-chart of designed system

All tests have been conducted in outdoor conditions. The ambient temperature was $0 \sim 37{ }^{\circ} \mathrm{C}$. The relative humidity was $46.5 \% \sim 95.3 \%$, and the amount of irradiation amount was also measured. The experimental seawater is the simulated seawater configured by tap water. The experiment was carried out under steady state and without regenerative conditions. The effect of water temperature, ambient temperature, air flow rate and air temperature on desalination performance was investigated. Under this condition, the water production rate of the system, and the impact of various factors on the system was studied. Finally, we did calculate the thermal efficiency of the experimental device.

\section{System thermal efficiency calculation}

In this paper, the performance of the solar desalination system is evaluated by the water production and thermal efficiency. The ratio of the theory heat required to obtain the fresh water theory and the actual heat obtained by the system is defined as the thermal efficiency, as given following:

$$
\eta=M_{w} \cdot h_{f g} \cdot Q^{-1}
$$


Where, Mw denotes fresh water yield $\left(\mathrm{kg} \cdot \mathrm{h}^{-1}\right)$; hfg represents water vapor latent heat, approximately $(2300$ $\left.\mathrm{kJ} \cdot \mathrm{kg}^{-1}\right)$; and Q indicates Amount of solar radiation $\left(\mathrm{KJ} \cdot \mathrm{h}^{-1}\right), \mathrm{Q}$ can be express by following equation:

$$
\mathrm{Q}=\mathrm{E} \cdot \mathrm{A}
$$

Where, E and A denote the intensity of the solar radiation $\left(\mathrm{KJ} \cdot \mathrm{m}^{-2} \cdot \mathrm{h}^{-1}\right)$, and the collector area $\left(\mathrm{m}^{2}\right)$.

\section{The relationship between the amount of radiation and the temperature}

The relationship between the local solar radiation and the temperature of the heated gas from SAC was tested as shown in Fig. 6.

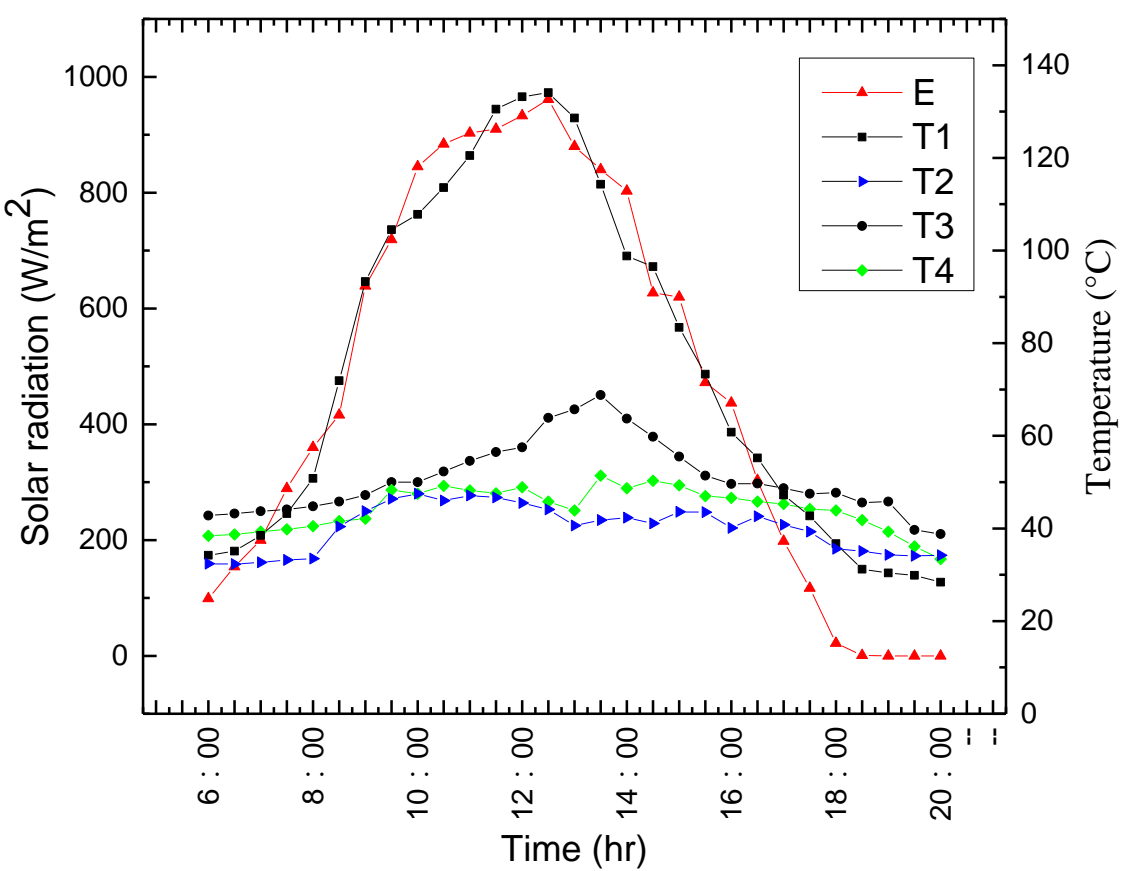

Fig. 3. Solar radiation, inlet, outlet water and air temperatures at humidifier at air flow rate of $14 \mathrm{~m}^{3} / \mathrm{h}$

The intensity of solar radiation increases firstly, reaches the maximum at 12:30 am, then decreases slowly, decreases to 0 after sunset at 19:00 pm. and the change trend of inlet air temperature (T1) is in synchronization with the irradiation intensity, the maximum radiation intensity reaches at maximum $134.2{ }^{\circ} \mathrm{C}$ (Fig.3). When the radiation intensity begins to weaken, the inlet temperature also begins to decrease, because the specific heat capacity of the air is small and sensitive to the change of the irradiation intensity. The fluctuation of outlet air temperature (T2) is smaller, and is above $34{ }^{\circ} \mathrm{C}$ to $48{ }^{\circ} \mathrm{C}$. After $18: 30$, the outlet temperature (T2) starts getting higher than the inlet air temperature (T1). This is because after the sunset, the temperature of the inlet air is rapidly reduced and while passing the hot sea water, the air absorbs the heat of the sea water, so the temperature of the air (T2) is slightly higher than the temperature of inlet air (T1). The temperature of the inlet water (T3) increases with the enhancement of irradiation intensity, and the temperature of the water increases continuously. After reaching the maximum value, the temperature of the water decreases with the decrease of the irradiation intensity. The change of the temperatureof the water is different from that change of the temperature of inlet air. The change of the temperature of water changes slower than that of solar irradiance. The maximum value of the temperature of water is delayed by $1.5 \mathrm{~h}$, compared with the change of the solar radiation and the maximum value is $68.9{ }^{\circ} \mathrm{C}$ at 13:30. In addition, it can be seen from the Fig. 3, the average temperature of the inlet air (T1) and inlet water (T2) are respectively $80.6{ }^{\circ} \mathrm{C}$ and $52.1{ }^{\circ} \mathrm{C}$, so the sea water of the system will not cause serious corrosion problems.

\section{Experimental results and discussions}


The system uses 10 ETCs. The area of ETCs is $2.0 \mathrm{~m}^{2}$. And the area of SACs is $1.0 \mathrm{~m}^{2}$. The entire desalination system is coated with anti-corrosion scale coating. In the course of the experiment the K-type thermocouple and other sensors are arranged in the measurement points that are used to measure the water temperature and gas temperature. The experiments were carried out under different ambient temperatures, different seawater temperatures, different intake air volumes, and whether the intake air was hot air. The system was designed for two-stage evaporator, and uses homogeneous aeration (microplate pannels), two-stage condensation. Under this condition, the water production rate of the system and the influence of each factor on the system were measured. The effluent quality was measured and compared, and the economic analysis of the device was completed.

\subsection{Effects of seawater temperature and air flow on water production rate}

When the hot air goes into the system with other factors remaining unchanged, the higher temperature of air makes faster evaporation of water. When the ambient temperature is about $15^{\circ} \mathrm{C}$ the rate of the water production in the system increases rapidly with increasing the temperatures as shown in Fig. 4 (a). When the intake air volume increases, the water production rate also increases as shown in Fig. 4 (b).

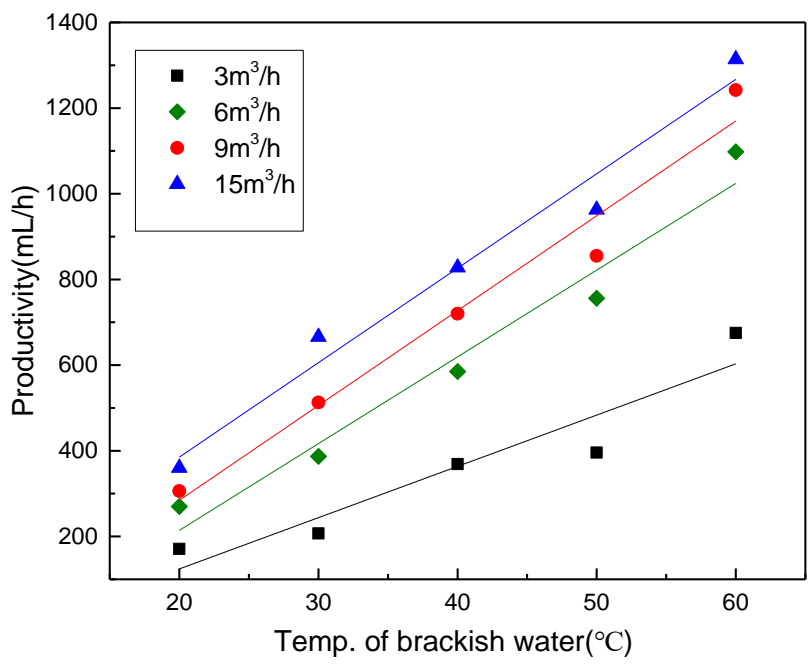

(a)

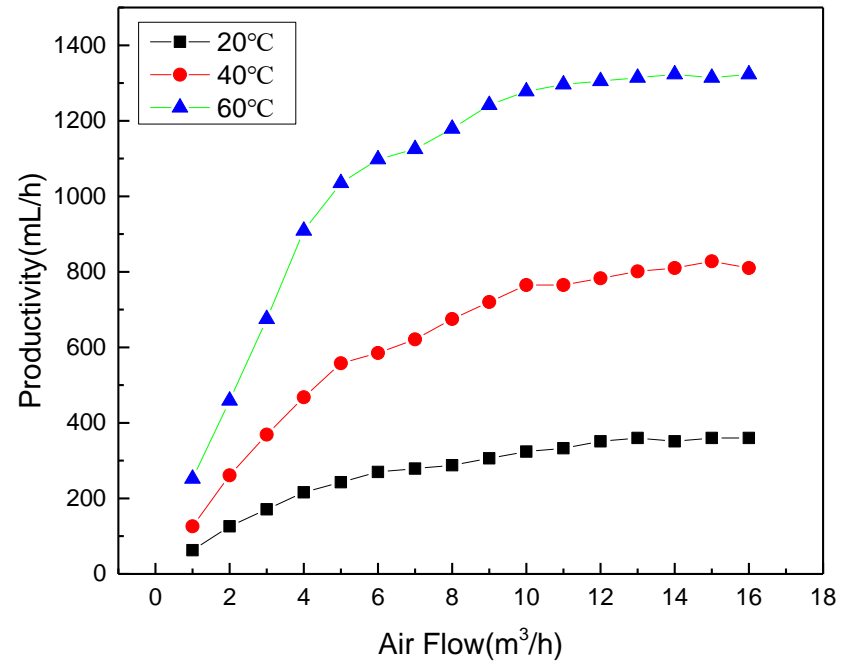

(b)

Fig. 4. (a) Productivity for different air flow and (b) Productivity for different temperature of the water 
Fig. 4 (a) shows that the relation of the water productivity with the seawater temperature and Fig.4 (b) shows the productivity curves with flow rate in three different seawater temperatures like $60{ }^{\circ} \mathrm{C}, 40{ }^{\circ} \mathrm{C}, 20{ }^{\circ} \mathrm{C}$. Fig. 3 illustrates the following two aspects: 1 . the rate of the water production increases with the water temperature and air flow rising, and the rate of water production is basically linear with the water temperature, the higher the sea water temperature, the faster the evaporation; 2. When the gas flow increases, the rate of water production increases, but when the air flow increases to a certain value, the rate of water production does not increase. When the gas flow continues to increase, sequentially larger gas flow will take away part of the heat in the evaporator, weaken the evaporation and on the other hand the larger gas flow makes the humidified gas quickly pass through the condensing devices, weaken the effect of the condenser. For the above reasons, it is expected that if the gas flow continues to increase, then the water production rate will no longer rise, but will decline.

\subsection{Effect of gas temperature on water production rate}

In the case of the water temperature of $60^{\circ} \mathrm{C}$, the gas flow and gas temperature influence the water production rate as shown in Fig. 5.

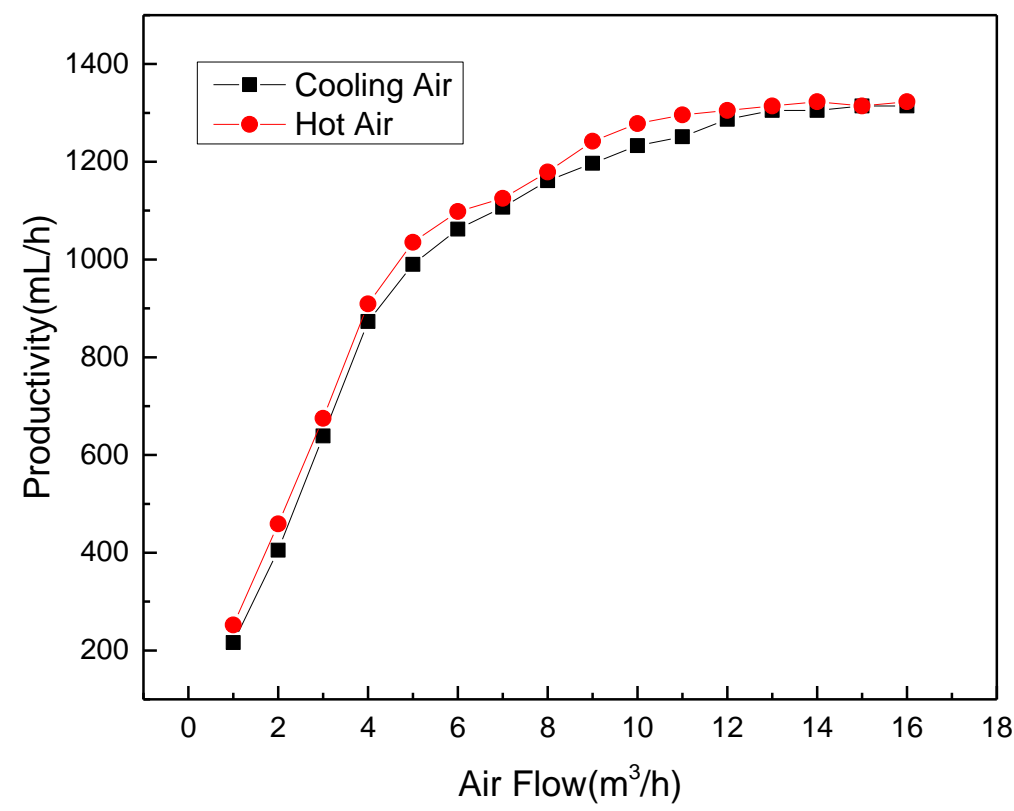

Fig. 5. Productivity with different rates of air flow with different temperature of the air

The two curves in the Fig. 5 show that different temperatures of the air have different effects on productivity. The hot air indicates that the air passes through the SAC and is heated. The cooling air indicates that the air doesn't pass through the SAC, and the temperature of the air is the same as the ambient temperature.

The SAC heats the gas which will go into the system because the temperature of the heated gas can reach 130 ${ }^{\circ} \mathrm{C}$. So, when the heated gas goes into the HUMs, the gas and the sea water will happen heat exchange, to promote the water temperature rise, to speed up the evaporation rate of sea water.

\subsection{The effect of ambient temperature on water production rate}

The effect of ambient temperature on water production performance of the system in the ambient temperature between $0{ }^{\circ} \mathrm{C}$ to $35^{\circ} \mathrm{C}$ was studied and the results are shown in Fig. 6. 


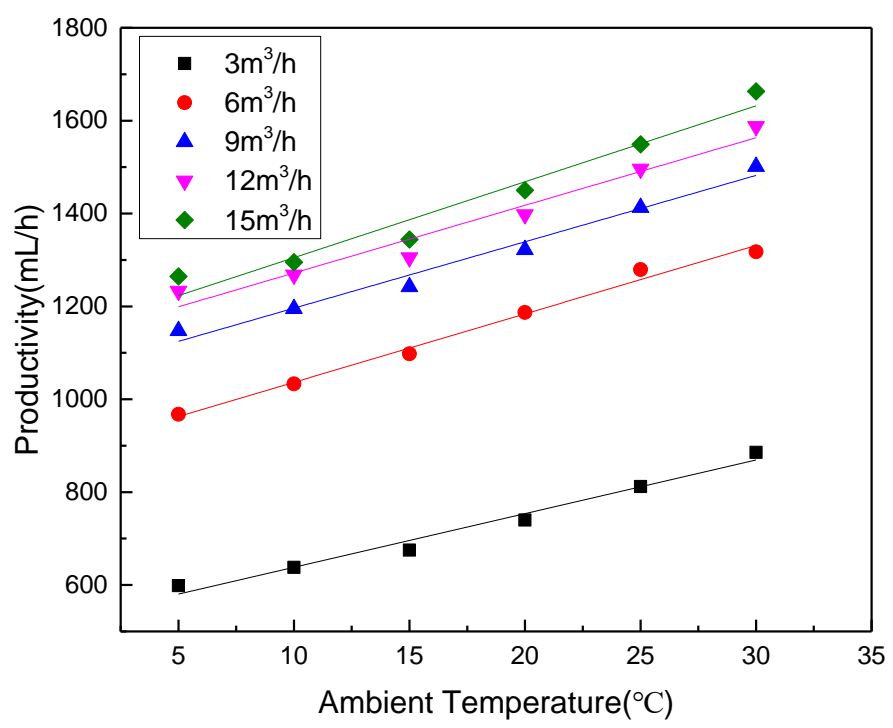

(a)

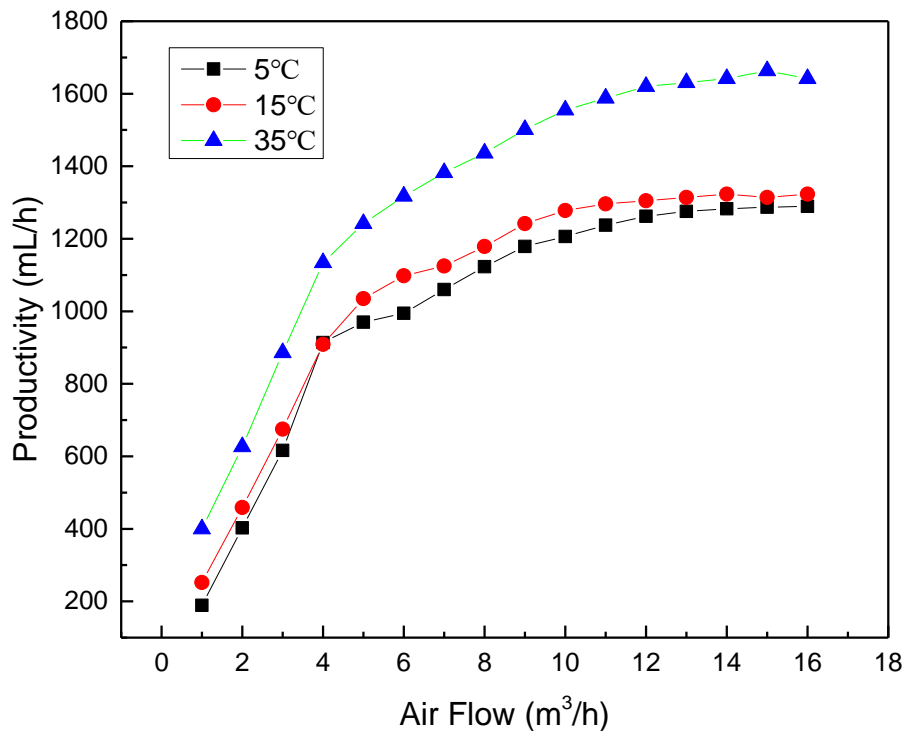

(b)

Fig. 6 . (a) Productivity for different ambient temperature (b) Productivity for different rate of air flow

When the ambient temperature rises, the effect of the condenser decreases. From this point of view, the water production rate should be reduced, but the experimental results show that the water production rate is rising. So the reason is analyzed, when the ambient temperature is low, the effect of the condenser is very good, but when the ambient temperature is lower (about $5{ }^{\circ} \mathrm{C}$ ), the heat of the hot gas that is heated by the SAC decreased so quickly in the steam before going into the HUMs (because the heat capacity of air is very small than water), so the heat exchange can be ignored heated between the gas and the water of the HUMs. Another important reason is that the temperature of the sea water in the second level of the HUM is also decrease so quickly. When the ambient temperature is $5^{\circ} \mathrm{C}$ and the sea water temperature of first level of HUMs is $60{ }^{\circ} \mathrm{C}$. The heat dissipation is larger between the two stages HUMs, most part of the heat is taken away by the gas, these two reasons result that the water temperature of the second level of HUM is only $40{ }^{\circ} \mathrm{C}$ to $45^{\circ} \mathrm{C}$, which lead to the water production of the system in the lower temperature $\left(5^{\circ} \mathrm{C}\right)$ is lower than that the water production of the system in the higher temperature $\left(30^{\circ} \mathrm{C}\right)$. 


\subsection{The quality of fresh water}

In this work the quality of the fresh water was also tasted, and the results were shown in Table $1 \& 2$. Analyze the data in the table. So the conclusion is the quality of fresh water is significantly better.

Table 1 The parameters of fresh water with different gas flow.

\begin{tabular}{cccc}
\hline Gas Flow $\left(\mathrm{m}^{3} / \mathrm{h}\right)$ & Salinity $(\mathrm{ppt})$ & TDS $(\mathrm{mg} / \mathrm{L})$ & Conductivity $(\mu \mathrm{s} / \mathrm{cm})$ \\
\hline 4.5 & 0.00 & 5.36 & 8.12 \\
7.0 & 0.00 & 6.21 & 8.68 \\
12.0 & 0.00 & 6.60 & 9.89 \\
15.0 & 0.00 & 7.01 & 11.23 \\
16.0 & 0.00 & 8.30 & 16.58 \\
\hline & Table 2 The parameters of fresh water. & \\
\hline Water of Lab. & Salinity (ppt) & TDS $(\mathrm{mg} / \mathrm{L})$ & Conductivity $(\mu \mathrm{s} / \mathrm{cm})$ \\
\hline Distilled Water & 0.00 & 2.41 & 4.24 \\
Drinking Water & 0.49 & 563.00 & 1132.00 \\
Tap Water & 0.54 & 589.00 & 1179.00 \\
\hline
\end{tabular}

\subsection{Calculation of system thermal efficiency $(\eta)$}

The total solar radiation of the experiment is $22.3 \mathrm{MJ} /(\mathrm{m} 2 \cdot \mathrm{d})$ and the total area of lighting is $3.0 \mathrm{~m} 2$. The total solar radiation $(\mathrm{Q})$ received by the solar collector is $67.2 \mathrm{MJ} / \mathrm{d}$.The accumulated fresh water production is $16.6 \mathrm{~kg} / \mathrm{d}$. Calculated by the formula (1), the system's thermal efficiency is 0.66 . Table 3 shows the thermal efficiencies of HDH systems reported by different scientist previously, the results show that the system of water production reaches $6.4 \mathrm{~L} /(\mathrm{m} 2 \cdot \mathrm{d})$ that is significantly higher than the results of predecessors.

Table 3 Performance Comparison between different solar HDH systems

\begin{tabular}{ccccc}
\hline Researchers & Process characteristics & Water yield per unit area & Thermal efficiency $(\eta)$ & Years \\
\hline Zhani [13] & Flat plate collector & $0.77 \mathrm{~L} /\left(\mathrm{m}^{2} \cdot \mathrm{d}\right)$ & - & 2010 \\
\hline M. Zamen [18] & Only ventilated & $3.67 \mathrm{~L} /\left(\mathrm{m}^{2} \cdot \mathrm{d}\right)$ & 0.41 & 2010 \\
\hline A. Khalil [6] & $\begin{array}{c}\text { Microplate aeration, } \\
\text { the system insulation }\end{array}$ & $4.8 \mathrm{~L} /\left(\mathrm{m}^{2} \cdot \mathrm{d}\right)$ & 0.53 & 2014 \\
\hline Pooria Behnam [1] & Air bubble column & $6.275 \mathrm{~L} /\left(\mathrm{m}^{2} \cdot \mathrm{d}\right)$ & 0.65 & 2016 \\
\hline Present work & $\begin{array}{c}\text { Two-stage, air } \\
\text { bubble, } \\
\text { heat preservation, } \\
\text { SAC, photovoltaic- } \\
\text { photothermal }\end{array}$ & $6.4 \mathrm{~L} /\left(\mathrm{m}^{2} \cdot \mathrm{d}\right)$ & 0.66 & 2017 \\
\hline
\end{tabular}

\section{Economic analysis}

The main economic advantages of solar desalination is, it dose not require much infrastructure, and simple to locally design with locally available materials, easy operation and maintenance [7]. The price of raw materials in the experiment was determined according to the market price in China, shown in Table 4 [1]. Table 4 shows that this system has a lower cost of producing fresh water with less land occupation and a greater advantage in oceangoing vessels and islands.

Table 4 Economic analysis of developed system.

\begin{tabular}{lcc}
\hline Parameter & Unit & Value 2 \\
\hline Capital cost $(\mathrm{P})$ & $\$$ & 3770 \\
Salvage value $(\mathrm{S}=0.2 * \mathrm{P})$ & $\$$ & 754 \\
Life $(\mathrm{n})$ & Year & 10 \\
Interest rate $(\mathrm{i})$ & $\%$ & 12 \\
Capital recovery factor $(\mathrm{CRF})$ & - & 0.134 \\
Sink fund factor $(\mathrm{SFF})$ & - & 0.043 \\
First annual cost $(\mathrm{FAC}=\mathrm{P} \times \mathrm{CRF})$ & $\$$ & 505 \\
Annual salvage value $(\mathrm{ASV}=\mathrm{SFF} \times \mathrm{S})$ & $\$$ & 21.7
\end{tabular}


Annual maintenance cost $(\mathrm{AMC}=0.15 \times \mathrm{FAC})$

Annual current cost $(\mathrm{ACC}=\mathrm{CC} \times$ Power $)$

Annual cost $(\mathrm{AC}=\mathrm{FAC}+\mathrm{AMC}+\mathrm{ACC}-\mathrm{ASV})$

Annual yield $(\mathrm{M}=$ average daily yield $\times 365)$

Cost per liter $(\mathrm{CPL}=\mathrm{AC} / \mathrm{M})$

\begin{tabular}{cc}
$\$$ & 75.75 \\
$\$$ & 0 \\
$\$$ & 559.05 \\
$\mathrm{~L}$ & 7008 \\
$\$ / \mathrm{L}$ & 0.08 \\
\hline
\end{tabular}

\section{Conclusion}

In order to improve the water production and thermal efficiency of the humidification dehumidification desalination system here we designed and developed a new type of solar desalination system. By increasing the evaporation area of seawater, the water production capacity of the system is increased and the area of the experimental device is reduced. The effects of solar radiation intensity, ambient temperature, air flow rate, air temperature and sea water temperature on the water production rate were determined. The optimal working parameters of the system have been improved. Following conclusions drawn from this work are enlisted bellow:

1) Significant improvement of water production rate, $1.4 \mathrm{~L} / \mathrm{h}$ at $60{ }^{\circ} \mathrm{C}$ temperature.

2) Best water production performances with $14 \mathrm{~m} 3 / \mathrm{h}$ air flow rate in summer condition.

3) The maximum water production rate is $1.6 \mathrm{~L} / \mathrm{h}$, maximum cumulative water production is $19.2 \mathrm{~L} / \mathrm{d}$ and the thermal efficiency is 0.66 .

4) The water consumption per unit area of the system is $6.4 \mathrm{~L} /(\mathrm{m} 2 \cdot \mathrm{d})$, which is $1.0-2.7$ times of the previous results and the water production performance is much better.

5) The system covers an area of less than 10 square meters, it does not require high-tech, so their design, construction and operation are easy because of the modular nature of the system.

6) This system has a lower cost of producing fresh water with less land occupation and a greater advantage in ocean-going vessels and islands.

\section{References}

[1] Behnam P, Shafii M B. Examination of a solar desalination system equipped with an air bubble column humidifier, evacuated tube collectors and thermosyphon heat pipes. Desalination, 2016, 397:30-37.

[2] Kabeel A E, Hamed A M, Elagouz S A. Cost analysis of different solar still configurations. Energy, 2010, 35(7):2901-2908.

[3] Ahmed H A, Ismail I M, Saleh W F, et al. Experimental investigation of humidification-dehumidification desalination system with corrugated packing in the humidifier. Desalination, 2017, 410:19-29.

[4] Ali M T, Fath H E S, Armstrong P R. A comprehensive techno-economical review of indirect solar desalination. Renew. Sust. Energ. Rev. , 2011, 15(8):4187-4199.

[5] Srithar K, Rajaseenivasan T, Karthik N, et al. Stand alone triple basin solar desalination system with cover cooling and parabolic dish concentrator. Renew. Energ. , 2016, 90:157-165.

[6] G. Prakash Narayan, Mostafa H. Sharqawy, Edward K. Summers, et al. The potential of solar-driven humidification-dehumidification desalination for small-scale decentralized water production. Renew. Sust. Energ. Rev. , 2010, 14(4):1187-1201.

[7] Yıldırım C, İsmail Solmuş. A parametric study on a humidification-dehumidification (HDH) desalination unit powered by solar air and water heaters. Energ. Convers. Manage. , 2014, 86(86):568-575.

[8] L. Zhang, S. Gao, H. Zhang, Experimental researches of factors affecting bubbling humidification, in: D. Jin, S. Lin (Eds.), Advances in Computer Science, Intelligent System and Environment, Springer Berlin Heidelberg, Berlin, Heidelberg 2011, pp. 359-364.

[9] Khalil A, El-Agouz S A, El-Samadony Y A F, et al. Solar water desalination using an air bubble column humidifier. Desalination, 2015, 372:7-16.

[10] Zamen M, Soufari S M, Vahdat S A, et al. Experimental investigation of a two-stage solar humidificationdehumidification desalination process. Desalination, 2014, 332(1):1-6.

[11] Abd-Ur-Rehman H M, Al-Sulaiman F A. An experimental investigation of a novel design air humidifier using direct solar thermal heating. Energ. Convers. Manage. , 2016, 127:667-678.

[12] Tabrizi F F, Khosravi M, Sani I S. Experimental study of a cascade solar still coupled with a humidification-dehumidification system[J]. Energ. Convers. Manage. , 2016, 115:80-88.

[13] Zhani K, Bacha H B. Experimental investigation of a new solar desalination prototype using the humidification dehumidification principle. Renewable Energy, 2010, 35(11):2610-2617.

[14] El-Agouz SA, Abugderah M. Experimental analysis of humidification process by air passing through seawater. Energ. Convers. Manage. , 2008;49(12):3698-703 
[15] El-Agouz S A. Desalination based on humidification-dehumidification by air bubbles passing through brackish water. Chem. Eng. J. , 2010, 165(2):413-419.

[16] Wang J H, Gao N Y, Deng Y, et al. Solar power-driven humidification-dehumidification (HDH) process for desalination of brackish water. Desalination, 2012, 305(9):17-23.

[17] He W F, Xu L N, Han D. Parametric analysis of an air-heated humidification-dehumidification (HDH) desalination system with waste heat recovery. Desalination, 2016, 398:30-38.

[18] Zamen M, Amidpour M, Rezakhani N. Theoretical and experimental investigation of humidification process in supersaturated state. Desalination, 2015, 369:165-174. 